\title{
Minimum Dietary Diversity and Associated Factors among Children Aged 6-23 Months in Enebsie Sar Midir Woreda, East Gojjam, North West Ethiopia
}

Dejenu Assefa ( $\square$ assefadeje@gmail.com )

Bahir Dar University

\section{Tefera Belachew}

Jimma University

\section{Research Article}

Keywords: Minimum Dietary Diversity, Infant and Young child feeding, associated factors, Enebsie Sar Midir

Posted Date: January 24th, 2022

DOl: https://doi.org/10.21203/rs.3.rs-1177378/v1

License: (c) (i) This work is licensed under a Creative Commons Attribution 4.0 International License.

Read Full License 


\section{Abstract}

Background - Dietary diversity has been recognized as a significant component of high-quality diets for children growth and development. Poor infant and young child feeding practices in the first one thousand days of age is the major contributor of malnutrition that leads to failure to thrive to their age, in low income countries including Ethiopia. It results in permanent outcomes of chronic malnutrition like stunting, affects intellectual development, and increases significantly the risks of many infectious diseases and death. There was no study that documented dietary diversity of children in the study area.

Objective - The main objective of this study was to assess minimum dietary diversity and associated factors among children.

Methods - Community based cross sectional study design was used to assess the minimum dietary diversity and associated factors among children aged 6-23 months in Enebsie Sar Midir Woreda, East Gojjam, North West Ethiopia. A total of 512 Mothers/care givers of with children of 6-24 months old in the community were included in the study using systemic sampling technique. Data were collected by interviewer administered structured, pre tested questionnaire. A 24 hour recall method was used to capture the dietary intake of children during the previous 24 hours period before the interview. The data were coded and entered into SPSS for windows version 20 and analyzed after cleaning. Descriptive statistics and bivariate and multivariable logistic regression models were used to isolate independent predictors of minimum dietary diversity. All tests were two sided and $\mathrm{P}<0.05$ was used for declaring statistical significance.

Results-The overall prevalence minimum dietary diversity was $18.2 \%$ (Cl: 14.8, 21.7). On multivariable logistic regression model, after adjusting for other variables, availability of cow's milk at household (AOR $=17.27 ; 95 \% \mathrm{Cl}: 6.73,44.44)$, cultivating vegetables (AOR $=3.2 ; 95 \% \mathrm{Cl}: 1.05,9.8)$, availability of farmland $(A O R=10.15,95 \% \mathrm{Cl}: 178,57.93)$ and number of animals (AOR $=6.46 ; 95 \% \mathrm{Cl}: 1.97,21.12)$ were significantly associated with minimum dietary diversity. The dominant food groups consumed were roots, grains and tubers. While consumption of vitamin A rich fruits and vegetables and other vegetables were relatively low.

Conclusion- The proportion of Infant and young children aged between 6-23months receiving minimum dietary diversity score is low compared with study conducted in Addis Ababa . Availability both animal and plant source foods from household's production were positively associated with practicing the minimum dietary diversity among children implying the need for strengthening nutrition sensitive agricultural practices.

\section{Background}

Adequate nutrition allows children to achieve proper milestone, to develop, grow, attain learning, and play, while under nutrition negatively affects children's total growth and development. Stunting is one of the 
main reason that affects the children mentally and physically leading to impairment of their physical growth and development of their full intellectual potential(1)

The government of Ethiopian has been employing the national nutrition program, Infant and Young Child Feeding (IYCF) strategy and has developed a multi-sectorial plan of nutrition intervention, Seqota Declaration, which targets the underlying, basic and immediate causes of malnutrition to end child under nutrition in Ethiopia by 2030 (2). Even though the government of Ethiopia has been doing several interventions including information dissemination via different media about the importance; the practice of feeding diversified food is still low as shown by different studies $(3-10,15)$.

A cross sectional study conducted in Mekele indicates inappropriate complementary feeding practices remain as major public health problem in many developing countries where many children are victim of the malpractice(13). Less than one-third of 6-23 months old children met the minimum criteria for dietary diversity. (14) .

A health facility based cross sectional study conducted in Addis Ababa on minimum dietary diversity shows that children with minimum dietary diversity were $59.9 \%$. Mother's educational attainment and a higher household monthly income were positively associated with the minimum dietary diversity practice. Similarly, mothers' knowledge on dietary diversity and child feeding were positively associated with minimum dietary diversity oOf children(15) .

A study conducted on nutritional status and dietary diversity of children below two years in Kasungu and Mzimba, Malawi have shown Minimum dietary diversity were 60\% (16).

A community-based cross sectional cluster survey was carried out in northern Ghana shows $34.8 \%$ received minimum dietary diversity ( $\geq 4$ food groups)(17)

Several cross sectional survey conducted in Asia and China have shown approximately half of all children met the MDD, varying from $47.7 \%$ in Cambodia to $58.2 \%$ in Indonesia, $24.6 \%$ in Myanmar and breastfeeding (51.7\%) than non-breastfeeding (71.9\%) in China (18-19).

In Ethiopia, over the past 15 years, remarkable decline in child under-nutrition had been observed. Childhood malnutrition still remains a major public health challenge in Ethiopia. As of 2019 Ethiopian Mini Demographic and Health Survey reported that $37 \%, 21 \%$ and $7 \%$ of under five years children were stunted, underweight, and wasted, respectively (11). This is hypothesized to be even worse in Amhara Region (the study area) due different social factors such as fasting animal source foods, which also obliges the child to fast.

A meta-analysis conducted in Ethiopia on dietary diversity and feeding practice among children age from 6 to 23 months result showed that the pooled prevalence of dietary feeding practice among children age 6-23 months in Ethiopia was $23.25 \%$. In the subgroup analysis, the lowest prevalence was observed in Amhara region (study area) (12.58\%) (12). 
Best search of literature showed that Minimum Dietary Diversity and associated factors have not been widely studied so far among children 6-23 months in Enebsie Sar Midir Woreda. Thus, this study identified the minimum dietary diversity and associated factors in Enebsie Sar Midir Woreda.

\section{Subjects And Methods}

\section{Study sample}

The study area was stratified into urban (Mertu le Mariam city) and rural, and two kebeles from the city and eleven kebeles from the rural communities were selected.

The study was conducted in Enebsie Sar Midir Woreda, East Gojjam Zone, North West Ethiopia. Systematic random sampling was used to select the study subjects in the community. As households were sampling units the sampling interval was obtained by dividing the total number of households of 19122 by the sample size. The first household was randomly selected within the interval of ten using lottery method. Then a bottle was tossed in the middle of each kebele after deciding to follow the head of the bottle. Then the households were counted in the direction of the head of the bottle to identify the first household. After that the next households were selected by adding the interval. In the evenbet where there is no eligible person within the selected household, the immediate next household was visited and this continued until the whole sample size was fulfilled. A structured questionnaire was used and prepared for face-to-face interviews to collect data from the study participants. The questionnaire were contained all the variables included in this study.

\section{Measurements}

The structured interview questionnaire was adapted from WHO IYCF indicators and other related scholars to the specific settings considering the objective of the study. The questionnaire was modified according to the study variable included and specific context. The questionnaire was prepared in English first and then it is translated in to Amharic by experts who work on this area before data collection. Pretest was done on $5 \%$ of the total sample of the study subject to ensure that the language and contents are culturally suitable, acceptable, and clearly understandable for the participants. Before data collection took place necessary corrections were made on the questionnaire to ensure the quality. During data collection, double checking the questionnaires was employed by the principal investigator.

A one day training was conducted for all research team members on data collection methods, tool pretesting and reflection. The contents of the training included privacy assurance, confidentiality, interview techniques, and reviews of the study protocol and questionnaire. Research team members were also equipped with quality control skills such as rechecking and reviewing the questionnaires after administration as well as resolving issues that might arise during the fieldwork.

"Minimum Dietary Diversity: is the consumption of four or more food groups from the seven food groups for higher dietary quality and to meet daily energy and nutrient requirements of the seven recommended 
food groups namely: grains, roots and tubers; legumes and nuts; dairy products; flesh foods (meat, fish, poultry and organ meats); eggs; vitamin-A rich fruits and vegetables; other fruits and vegetables".(20).

The data collection started from identifying the study subjects and selected randomly who was included in the study. The data collection was conducted by using 24 hour recall method in the community from mothers or care givers. All participants who fulfill the criteria were participated. Then oral informed consent was conducted.

The data collectors were grade 10 and 12 complete persons who have previous data collection experience in health care program areas. Before the data collection, the principal investigators had given basic training about the questionnaire. Thus, all data collectors know about the objectives of the study, the data collection approach, the discipline need to have during data collection and other important issues related to the problem.

The principal investigator and health extension workers were recruited the supervisor purposively. These persons were familiar about the overall information needed, about the purpose of this research as a supervisor to guide the data collectors, about the time of collection and how to manage the study subjects during data collection procedure. The principal investigator closely followed data collection procedure. Completed questionnaires were rechecked for completeness and consistency starting from the beginning of the data collection to provide feedback for the next steps of the data collection throughout the of the data collection period.

Wealth index was generated by asking durable assets including radio, TV, mobile phone, hand cart, plough plow. Ownership of each asset was given a score of " 1 " and non ownership was given a score of " 0 ". Principal component analyses was conducted to generate wealth index after checking all assumptions such as sample adequacy ( $\mathrm{KMO} \geq 0.5$, antiimage $\geq 0.5$ and communality $\geq 0.5$, Bartlets test of Sphericity $(P<0.5)$ and absence of variable with complex structure. The wealth index score was then rank ordered into tertiles and the highest terile was taken as rich while the two lowest teriles combined were taken as poor.

\section{Data analysis}

Data analysis plan: the data were entered in Epi INFO version 7 and transferred in to statistical package for social science (SPSS) Version 20.The data were cleaned and analyzed using SPSS for windows version 20 (Illinmoise Chicago). Frequency table was used to show the background variables. Percentages and table were used describe result of the study. Chi square was used to examine the relationship between minimum dietary diversity and associated factors. $\mathrm{P}<0.05$ was considered statistical significance. Bivariate and multivariabe logistic regression analysis were employed. Variables that had $P$ value less than 0.25 in the bivariate model were entered into the multivariable regression model. Different factors were regressed with minimum dietary diversity as dependent variable to isolate its independent predictors. Model fitness was checked using Hosmer Lemeshaw test at $P>0.05$. 
Multicolliniary was checked using standard error $\geq 2.0$. The results are presented using adjusted Odds Ratios and $95 \%$ confidence intervals

\section{Results}

Out of the total 530 sampled mothers/care takers who had children age from 6-23 months, 512 of participated in the study with the response rate of $96.6 \%$. The mean $(\underline{+s d})$. age of mothers/caregivers was $32( \pm 6.1)$ years. Out of the total respondents (mothers) interviewed, over half $(55.7 \%)$ of them were between the age group of 25-34 years. From all variables recruited, twenty two variables were significantly associated with minimum dietary diversity on bivariate logistic regression analysis. (Table 1)

Bivariate analyses showed that significantly higher proportion (88.1\%) households did not practice minimum dietary feeding than household residue in urban area (12.9\%), $\mathrm{P}<0.001$.

Educational status of the mother was significantly associated with minimum dietary practice of mothers who completed higher education were likely to feed diversified diet than illiterate mothers $(78.2 \%),(\mathrm{P}<$ 0.001). Similarly, $5.3 \%$ of mothers who were office workers practiced minimum dietary diversity compared to house wife or house workers. A larger proportion (86.1\%) of children from households greater than four family size also reported that they did not get diversified food compared to households with less than four family size (13.9\%), $(P<0.001)$.

Minimum dietary feeding practice was significantly higher among households with availability of Media Source at home (29.9), compared to those children's from household with no availability of media source at home $(70.1 \%),(P<0.001)$. A significantly $(P<0.001)$ higher proportion $(50.2 \%)$ of children form households with number of under-five children in the household of greater than two did not get proper diversified diet, compared to those form households with number of under-five children's less than two (49.8\%).

From a total of twenty-two variables considered for the bivariate analysis, only cultivating vegetables, having cow milk, availability of farm land and number of animals were significantly associated with minimum dietary diversity in the multivariable logistic regression model.

On multivariable logistic regression model, after adjusting for other variables, those mothers who from households that cultivate vegetables were 3.2 times (AOR=3.2, 95\% Cl: $1.05,9.8)$ more likely to feed their children with optimum dietary diversity compared to those who do not cultivate vegetables. Those who had cow's milk in the household were 17.27 times (AOR= 17.27, 95\% Cl: 6.73, 44.44) more likely to feed their children with optimum dietary diversity. Women (parents) who had farmland were 10.1 (AOR=10.15, $95 \% \mathrm{Cl}: 178,57.93)$ times more likely to feed their children. Those women (parents) who had number of animals six to ten were 6.46 times more likely to feed their children with optimum dietary diversity compared to those who had number of animals less than five( $\mathrm{AOR}=6.46,95 \% \mathrm{Cl}: 1.97,21.12)$. The likelihood of feeding optimum dietary diversity to their children was 15 times more (AOR=15.12, 
$95 \%$ Cl:4.31, 53.05 ) among mothers (parents) who had number of animals greater than ten compared to those who had number of animals less than five. (Table 2)

\section{Food groups consumed in 24 hours}

The study showed grain, roots and tubers were the most commonly consumed food items 24 hours prior to the survey followed by eggs; i.e., it is consumed by 485 (94.7\%) and 187 (336.5\%), respectively. However, the consumption of vitamin A rich fruits and vegetables was low. From the total children only 91 (17.8\%) consumed Vitamin A rich fruits and vegetables. (Figure1).

\section{Minimum Dietary Diversity}

All mothers included in this study had started giving solid, semi-solid or liquid foods for their children and all of the children had received complementary foods before the day of the study. The frequency of children who had received minimum dietary diversity within 24 hours previous data collection was 18.2 $\%$. ( $\mathrm{Cl} ; 14.8,21.7)$. Two hundred eighteen $(42.6 \%)$ of the sampled children took one types of food at the time of survey on the 24 -h recall followed by two meals $(26.4 \%)$ while the frequency of children who consumed three meals was $12.9 \%$.

\section{Discussion}

The results showed that $18.2(95 \% \mathrm{Cl} ; 14.8,21.7)$ of the children aged 6-23 months had four or more food groups meeting the minimum requirement of dietary diversity. Studies showed different magnitudes among children aged $6-23$ months in Ethiopia $(21,22,7,24)$. Similarly, the magnitude of minimum dietary diversity is different in different countries $(7,17,19)$. This finding is similar to a study conducted in southern Ethiopia (23); however, it is higher than the reported national of EDHS 2016 and some other national studies (11). The finding is lower than other studies done in Addis Ababa, Ghana, Indonesia, and Myanmar $(15,17,24,25)$. A study conducted in Sinan Woreda found that only $13 \%$ of children had met the minimum dietary diversity (22). Feeding of vitamin rich fruits, dairy products, flesh, and vegetables and other fruits was low. This was similar with the studies done in Ethiopia (26). The possible reason might be cereals, grains and tubers are the commonest products in the study area, while the unavailability of these food sources (vitamin rich fruits, dairy products, flesh, and vegetables and other fruits was low) at household level; in which commonly consume those food items they cultivated and accessed from the market in low cost.

The difference in dietary diversity might be due to paternal educational level, socio-economic difference and geographical variation between the study areas. The possible reasons for low dietary diversity practices in the study area could be that mothers 'or care givers might not have adequate access to media and information related to diversified diet and child feeding practices, low practice of giving different types of food after six months, income shortage to buy foods that are not available at home and the habit or culture of the family, i.e. there is no specific types of food prepared for children and also those foods which are costy are not used by the their children rather sold to earn some money. Animal source 
foods are not also commonly used as routine types of food instead they get consumed during holidays or events like wedding.

This study found out that cultivating vegetables, availability of cow milk, available farmland and number of animals were factors associated with meeting MDD.

The likelihood of feeding children with optimum dietary diversity was more among mothers who cultivated vegetables at household. This might be due to easy accessibility of vegetables. Mothers or care givers who had available cow's milk at household level were more likely to feed diversified food group than those who had not. The possible reason might be the household that have cow's milk, feed their child milk and milk products in addition to the common diet. Similar result has been reported by the study conducted in Ethiopia (22).

Unlike previous studies which was conducted in Ethiopia and Ghana $(7,17)$ there is no association between maternal education and minimum dietary diversity in this study. There is no association between wealth index, maternal age and minimum dietary diversity in this study. This result is supported by similar study conducted in Ethiopia (27), and also this study finding didn't show any association between maternal age and minimum dietary diversity unlike the study conducted in Robe Town, Bale Zone (26). The findings have practical implications for improving child feeding in the study area. Improving ownership of animals and land, availability of cow's milk in the household and production vegetables were significantly associated with MDDS, which is in alignment with the nutrition sensitive agricultural strategy and the national food and nutrition policy.

This study acknowledges the common limitations of cross sectional study. Effect of seasons on the minimum dietary diversity could not be assessed due to cross-sectional nature of the study. Accurately reporting participants; past feeding dietary habit could be a problem due to memory laps (recall bias) which was tried to be minimized by probing them during data collection. Including qualitative data would have added to the findings by capturing the how's and whys behind the numbers related to cultural issues in this study area, it was not done in this study.

\section{Conclusion}

The study showed important gap to meet optimal minimum dietary diversity. Based on findings of this study, the overall prevalence of optimum dietary diversity score among children aged 6- 23 months in Enebsie Sar Midir Woreda is low compared with other countries. To achieve the optimal minimum dietary diversity feeding practice for all children aged between 6 and 23 months in the study area it needs more work. Availability of cow's milk in the household, cultivating vegetables, availability of farm land and number of animals was significantly associated with optimal dietary diversity feeding practice of children aged 6-23 months. In this study consumption of fruits and vegetables was relatively low.

\section{Declarations}




\section{Ethics approval and consent to participate}

Ethical clearance was obtained from Institutional Review Board of Institute of Technology, School of Chemical and Food Engineering, Bahir Dar University; official letters is submitted to the ANRS regional health bureau. The regional health bureau ethical review board approves and gives formal letter to the East Gojjam Zone Health Office and the Zonal health bureau ethical review board approves and gives formal letter to Woreda Health Office. Supervisors and data collectors were trained on confidentiality. The purpose and importance of the study was explained to the study participants and verbal informed consent obtained from all participants before starting the interviews or taking body measurements and also, they are informed about the possibility to refuse participation at any time of data collection.

Editor-In-Chief of international breast-feeding journal

\section{Consent for Publication}

\section{Subject: Submitting a Manuscript}

We are submitting our manuscript entitled "Minimum Dietary Diversity and Associated Factors among Children Aged 6-23 Months in Enebsie Sar Midir Woreda, East Gojjam, North West Ethiopia" for publication in the Journal of International Breast Feeding. We wanted to publish the manuscript in Journal of International Breast Feeding to get relevant readers and make an impact in changing the policy for prevention of the rapidly emerging obesity and chronic non-communicable diseases in Ethiopia.

All authors have read the submitted version of the manuscript and do not have any conflict of interest. We declare that the manuscript is not submitted to any other journal simultaneously.

Best regards,

Dejenu Assefa (MSc)

Corresponding Author

E-mail: assefadeje@gmail.com

\section{Availability of Data and materials}

The datasets analyzed during the current study are available from the corresponding author on reasonable request.

\section{Competing interests}

The authors declare that they have no competing interests.

\section{Funding}


No funding was received from any organization for the research

\section{Authors Contribution}

\section{Contributions}

All authors designed the study and participated in the data collection questionnaire design. DA undertook the methodology part, funding of the cost of research, data collection supervision, data coding, cleaning, data analysis. All authors read and approved the final manuscript.

\section{Acknowledgment}

Special thanks are extended to the mothers and caregivers, Enebsie Sar Midir Woreda Health secretary director for his support and kindness of completing this study, health extension workers and data collectors who were participated in this study.

\section{References}

1. Jones AD, Ickes SB, Smith LE, Mbuya MN, Chasekwa B, Heidkamp RA, et al. W orld H ealth $O$ rganization infant and young child feeding indicators and their associations with child anthropometry: a synthesis of recent findings. Maternal \& child nutrition. 2014;10(1):1-17.

2. Centeral statistics of Ethiopia (CSA), [Ethiopia] Ethiopia Demographic and health survey, 2016. Addis Ababa, Ethiopia; 2016.

3. Gamo GS, Alemayehu M. Dietary diversity and associated factors among infants and young children in Wolaita Zone, Southern Ethiopia. Sci J Clin Med. 2017;6(4):53-9.

4. Gatahun EA, Demissie M, Abyu DM. Dietary diversity feeding practice and determinants among children aged 6-23 months in Kemba Woreda, Southern Ethiopia implication for public health intervention. J Nutr Food Sci. 2015;S13:S13003.

5. Gebremichael B, Egata G, Assefa N. Dietary diversity practice and associated factors among infants and young children in Haramaya town, Ethiopia. International Journal of Public Health Science (IJPHS). 2017;6(3):243-50.

6. Kumera G, Tsedal E, Ayana M. Dietary diversity and associated factors among children of orthodox Christian mothers/caregivers during the fasting season in Dejen District. North West Ethiopia Nutrition \& metabolism. 2018; 15:16.

7. Tegegne M, Benti T, Sileshi S, Teshome M, Woldie H. Factors associated with minimal meal frequency and dietary diversity practices among infants and young children in the predominantly agrarian society of Bale zone, Southeast Ethiopia: a community based cross sectional study. Open Access 2017; 140 
8. Liben M, Abuhay T, Haile Y. Factors associated with dietary diversity among children of agro pastoral households in Afar regional state. Northeastern Ethiopia, vol. 2017:5.

9. Gebremedhin S, Baye K, Bekele T, Tharaney M, Asrat Y, Abebe Y, Reta N: Predictors of dietary diversity in children ages 6 to 23 month in largely food insecure area of south Wollo, Ethiopia. Nutrition (Burbank, Los Angeles County, Calif) 2017, 33:163-168.

10. Agize A, Jara D, Dejenu G. Level of knowledge and practice of mothers on minimum dietary diversity practices and associated factors for 6-23-monthold children in Adea Woreda, Oromia. Ethiopia BioMed research international. 2017;2017:7204562.

11. Health FMo. Mini Demographic and Health Survey. In: Institute EPH, editor. Addis Ababa: Federal Ministry of Health; 2019.

12. Tassew AA, Tekle DA, Belachew AB, Adhena BM. Factors affecting feeding 6-23 months age children according to minimum acceptable diet in Ethiopia: A multilevel analysis of the Ethiopian Demographic Health Survey. Plos One, 14(2) e0203098.

13. Lutter CK, Daelmans BM, de Onis M, Kothari MT, Ruel MT, Arimond M, et al. Undernutrition, poor feeding practices, and low coverage of key nutrition interventions. Pediatrics. 2011;128(6):e1418e27.

14. Mekbib E, Shumey A, Ferede S, Haile F. Magnitude and factors associated with appropriate complementary feeding among mothers having children 6-23 months-of-age in northern Ethiopia; a community-based cross-sectional study. J Food Nutr Sci. 2014;2(2):36.

15. Solomon D, Aderaw Z, Tegegne TK. Minimum dietary diversity and associated factors among children aged 6-23 months in Addis Ababa, Ethiopia. International journal for equity in health. 2017;16(1):181

16. Kuchenbecker J, Reinbott A, Mtimuni B, Krawinkel MB, Jordan I. Nutrition education improves dietary diversity of children 6-23 months at community-level: Results from a cluster randomized controlled trial in Malawi. PloS one. 2017;12(4):e0175216.

17. Saaka M, Wemakor A, Abizari A-R, Aryee P. How well do WHO complementary feeding indicators relate to nutritional status of children aged 6-23 months in rural Northern Ghana? BMC public health. 2015;15(1):1157.

18. Isingoma BE, Samuel M, Edward K, Maina GW. Socioeconomic and demographic factors influencing feeding practices, morbidity status, and dietary intakes of children aged 7-24 months in rural Uganda. Ecology of food and nutrition. 2017;56(1):1-16.

19. Hipgrave D, Fu X, Zhou H, Jin Y, Wang X, Chang S, et al. Poor complementary feeding practices and high anaemia prevalence among infants and young children in rural central and western China. European journal of clinical nutrition. 2014;68(8):916.

20. World Health Organization. Indicators for assessing infant and young child feeding practices 2008 [Part l: definition]. Available from: http://www.who. Int/maternal_child_adolescent /documents/9789241596664/en/. 
21. Mekonnen TC, Workie SB, Yimer TM, Mersha WF. Meal frequency and dietary diversity feeding practices among children 6-23 months of age in Wolaita Sodo town, Southern Ethiopia. Journal of Health, Population and Nutrition. 2017;36(1):18.

22. Temesgen $\mathrm{H}$, Yeneabat $\mathrm{T}$, Teshome $\mathrm{M}$. Dietary diversity and associated factors among children aged 6-23 months in Sinan Woreda, Northwest Ethiopia: a cross-sectional study. BMC Nutrition. 2018;4(1):5.

23. Kassa T, Meshesha B, Haji Y, Ebrahim J. Appropriate complementary feeding practices and associated factors among mothers of children age 6-23 months in Southern Ethiopia, 2015. BMC Pediatrics. 2016; 16: 131.

24. Crookston B, Dr. Syafiq A, Hasan L, Torres S, Linehan M, Dr. Bennett C, Dr. Dearden K, Dr. West J, Hall C. Factors associated with dietary diversity and food frequency among Indonesian children. International social and behavior change communication summit. 2018

25. Kyaw Swa Mya, Aung Tin Kyaw, Thandar Tun. Feeding Practices and Nutritional Status of Children Age 6-23 Months in Myanmar: Further Analysis of the 2015-16 Demographic and Health Survey. 2018 No 136

26. Damtie SB. Dietary Diversity Practice and Associated Factors among Children Aged 6-23 Months in Robe Town, Bale Zone, Ethiopia. Journal of nutrition and metabolism. vol.2020

27. Dangura D, Gebremedhin S. Dietary diversity and associated factors among children 6-23 months of age in Gorche district, Southern Ethiopia: Cross-sectional study. BMC pediatrics. 2017;17(1):6.

\section{Tables}

Table1. Characteristics Mothers Having Child Aged 6-23 Months In Enebsie Sar Midr Woreda, March 2020. $(N=512)$ 


\begin{tabular}{|c|c|c|c|}
\hline \multirow[t]{2}{*}{ Characteristics $(n=512)$} & \multicolumn{2}{|c|}{ Minimum DDS } & \multirow[t]{2}{*}{$\mathbf{P}$} \\
\hline & Yes & NO & \\
\hline \multicolumn{4}{|l|}{ Marital Status(n=512) } \\
\hline Married & 89 & 425 & \\
\hline Unmarried & 4 & 4 & 0.04 \\
\hline \multicolumn{4}{|l|}{ Residence $(n=512)$} \\
\hline Urban & 50 & 16 & \\
\hline Rural & 43 & 403 & 0.001 \\
\hline \multicolumn{4}{|l|}{ Educational Status $(n=512)$} \\
\hline Higher education & 93 & 2 & \\
\hline Illiterate & 36 & 364 & 0.001 \\
\hline Primary & 21 & 48 & 0.001 \\
\hline Secondary & 17 & 5 & \\
\hline \multicolumn{4}{|l|}{ Current occupation(n=512) } \\
\hline House worker/house wife & 55 & 343 & \\
\hline Office worker & 24 & 3 & 0.001 \\
\hline Daily laborer & 5 & 22 & \\
\hline Merchant & 6 & 4 & 0.001 \\
\hline Farmer & 3 & 47 & \\
\hline \multicolumn{4}{|c|}{ Your wife/husband Current occupation( $n=512)$} \\
\hline House worker/house wife & 8 & 44 & \\
\hline Office worker & 36 & 2 & 0.001 \\
\hline Merchant & 12 & 10 & 0.001 \\
\hline Farmer & 33 & 357 & \\
\hline \multicolumn{4}{|c|}{ Household family size $(n=512)$} \\
\hline$<4$ & 20 & 51 & \\
\hline$>=4$ & 73 & 368 & 0.001 \\
\hline \multicolumn{4}{|c|}{ Number of under 5 children's $(n=512)$} \\
\hline$<2$ & 80 & 175 & \\
\hline$>=2$ & 13 & 244 & 0.001 \\
\hline
\end{tabular}




\begin{tabular}{|c|c|c|c|}
\hline \multicolumn{4}{|c|}{ Availability of media source at household $(\mathrm{n}=512)$} \\
\hline Yes & 63 & 90 & \\
\hline No & 30 & 329 & 0.001 \\
\hline \multicolumn{4}{|c|}{ Exposure to available media source $(n=512)$} \\
\hline Yes & 63 & 88 & \\
\hline No & 30 & 331 & 0.001 \\
\hline \multicolumn{4}{|c|}{ Available Farmland(n=512) } \\
\hline No & 52 & 11 & \\
\hline Yes & 41 & 408 & 0.001 \\
\hline \multicolumn{4}{|c|}{ Cultivating vegetables $(n=512)$} \\
\hline No & 80 & 400 & \\
\hline Yes & 13 & 19 & 0.001 \\
\hline \multicolumn{4}{|c|}{ Available livestock $(\mathrm{n}=512)$} \\
\hline Yes & 43 & 401 & \\
\hline No & 50 & 18 & 0.001 \\
\hline \multicolumn{4}{|c|}{ Having cow milk and feed the child $(n=512)$} \\
\hline No & 57 & 325 & \\
\hline Yes & 36 & 94 & 0.001 \\
\hline \multicolumn{4}{|c|}{ Agro ecology $(n=512)$} \\
\hline Dega & 9 & 107 & \\
\hline Woyinadega & 74 & 190 & 0.001 \\
\hline Kola & 10 & 122 & \\
\hline \multicolumn{4}{|l|}{ Wealth Index } \\
\hline Poor & 28 & 331 & \\
\hline Rich & 65 & 88 & 00.001 \\
\hline \multicolumn{4}{|c|}{ Number of Animals $(n=512)$} \\
\hline $0-5$ & 76 & 108 & \\
\hline $6-10$ & 7 & 110 & 0.01 \\
\hline$>10$ & 10 & 201 & \\
\hline
\end{tabular}


Table 2 Predictors of minimum Dietary Diversity practice

\begin{tabular}{|lll|}
\hline Characteristics & AOR & P \\
\hline Availability of media source at household $(\mathrm{n}=512)$ & & \\
\hline Yes & 1.00 & \\
\hline No & $10.15(1.78,57.95)$ & $<0.001$ \\
\hline Cultivating vegetables $(\mathrm{n}=512)$ & & \\
No & 1.00 & \\
Yes & $3.2(1.05,9.8)$ & $<0.001$ \\
\hline Having cow milk and feed the child $(\mathrm{n}=512)$ & & \\
No & 1.00 & \\
Yes & $17.27(6.73,44.44)$ & $<0.001$ \\
\hline Number of Animals $(\mathrm{n}=512)$ & & $<0.01$ \\
$0-5$ & 1.00 & $<0.001$ \\
$6-10$ & $6.46(1.97,21.12)$ & \\
\hline$>10$ & $15.12(4.31,53.05)$ & \\
\end{tabular}

\section{Figures}

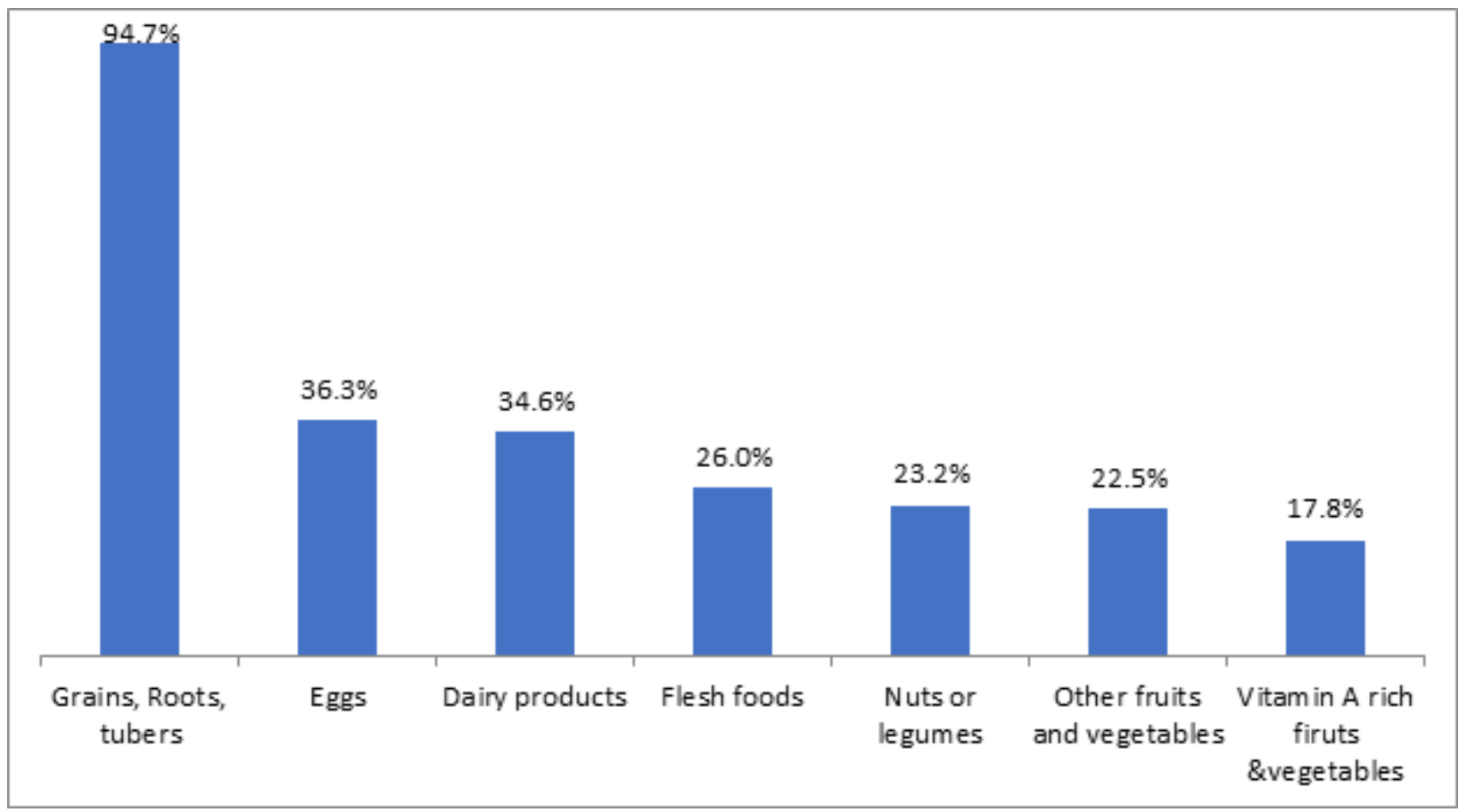


Figure 1

Types of food groups consumed by children aged 6-23 in Enebsie Sar Midr Woreda, march 2020 ( $n=512)$ 